\title{
Synthesis and Electrical Resistivities of the Complexes of Alkali-Metal- TCNQ Salts with a Crown Ether Polymer
}

\author{
Shigeo OHNISHI, Takashi NogAMI,* and Hiroshi MIKAWA \\ Department of Applied Chemistry, Faculty of Engineering, \\ Osaka University, Yamada-oka, Suita, Osaka 565, Japan
}

(Received August 13, 1982)

\begin{abstract}
KEY WORDS Electrical Resistivity / Tetracyanoquinodimethan / Crown Ether Polymer / Electronic Reflection Spectra /
\end{abstract}

Tetracyanoquinodimethan (TCNQ) is a typical electron acceptor, yielding a large number of conductive organic material. Some of the polymer complexes with TCNQ give conductive homogeneous films, and are useful in designing electronic devices. We synthesized about 100 kinds of cationTCNQ-crown ether complexes, and measured their electrical conductivities and electronic reflection specta. ${ }^{1}$ In an extension of this study, we also synthesized new polymer complexes with the TCNQ shown below as $(\mathbf{1}-\mathbf{4})$ using a crown ether polymer 5. We chose polymer 5 from many crown ether polymers, because of the ease of its synthesis and its film-forming ability. Electrical resistivities of homogeneous films of polymers 1, 2, 3, and 4 were measured at room temperature, and compared with

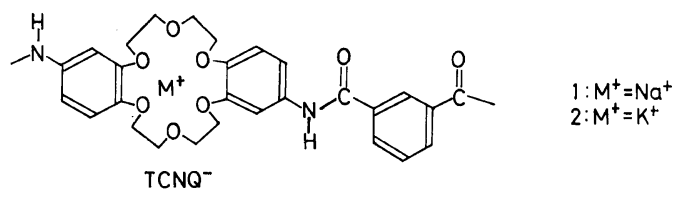<smiles>CNc1ccc(OCCOCCOc2cc(NC(=O)c3cccc(C(C)=O)c3)ccc2OCCOCCOCC#N)c(OCCOCC#N)c1</smiles><smiles>CNc1ccc(OCCOCCOCCOCCOc2cc(NC(=O)c3cccc(C(C)=O)c3)ccc2OCCOCCO)c(OCCO)c1</smiles>

those of polycation-TCNQ complexes ${ }^{2}$ (the most extensively studied of polymer complexes with TCNQ) and the original TCNQ salts. The relation between electrical resistivities and electronic reflection spectra of these polymer films is discussed in this paper.

\section{EXPERIMENTAL}

\section{Synthesis of Polymer Complexes}

Polymer 2. Polymer $\mathbf{5}$ was synthesized by reported procedures. ${ }^{3}$ Polymer 2 was obtained by dissolving $0.3 \mathrm{~g}$ of polymer 5 and $0.14 \mathrm{~g}$ of $\mathrm{K}^{+} \mathrm{TCNQ}^{-}(1: 1$ mole ratio) in $33 \mathrm{ml}$ of dimethylsulfoxide (DMSO) under a nitrogen atmosphere at room temperature. DMSO was distilled under vacuum at $80^{\circ} \mathrm{C}$, and the residue was dried at $80^{\circ} \mathrm{C}$ under vacuum for $24 \mathrm{~h}$. Polymer 1 was obtained by essentially the same method.

Polymer 4. Polymer $5(0.3 \mathrm{~g}), \mathrm{K}^{+} \mathrm{TCNQ}^{-}(0.14 \mathrm{~g}$, and TCNQ $(0.117 \mathrm{~g})(1: 1: 1$ mole ratio) were dissolved into DMSO $(40 \mathrm{ml})$. The subsequent procedure was the same as described above. Polymer 3 was obtained by the same method.

\section{Measurement of the Electrical Resistivity of the Polymer Film}

A DMSO solution containing a given TCNQcrown ether polymer was filtered, and the filtrate was cast on a copper plate. The plate was placed in a glass vessel, and the vessel was evacuated gently at $30^{\circ} \mathrm{C}$ for $5 \mathrm{~h}$ to obtain a homogeneous film. ${ }^{4}$ Gold electrodes were deposited on the surfaces of the 
polymer film by evaporation. The electrical resistivity was determined from the voltage difference between the two electrodes generated by applying a constant current across the polymer film.

\section{RESULTS AND DISCUSSION}

\section{Synthesis of Polymer Complexes}

Polymer complexes 1, 2, 3, and 4 gave homogeneous films when their DMSO solution was cast onto a metal plate or a nesa glass plate, and dried in vacuo at $30^{\circ} \mathrm{C}$. The films of $\mathbf{1}$ and 2 were green, and those of $\mathbf{3}$ and $\mathbf{4}$ dark green. These films were stable in vacuum or in an argon atmosphere, but became unstale in the air, changing gradually to dark brown. We tried to obtain polymer complexes by the use of $\mathrm{Li}^{+} \mathrm{TCNQ}^{-}, \mathrm{Ba}^{2+}\left(\mathrm{TCNQ}^{-}\right)_{2}$, and $\mathrm{NH}_{4}^{+} \mathrm{TCNQ}^{-}$. However, these metal-TCNQ salts crystallized spontaneously in the films without yielding any homogeneous film.

\section{Electrical Resistivities}

Table I shows the electrical resistivities of complexes $1,2,3$, and 4 , together with the range of resistivity of polycation-TCNQ complexes and the resistivities ${ }^{5}$ of $\mathrm{Na}^{+} \mathrm{TCNQ}^{-}$and $\mathrm{K}^{+} \mathrm{TCNQ}^{-}$. Complexes, 3 and 4, were more electrically conductive than complexes $\mathbf{1}$ and 2 . Probably these findings reflect Coulombic repultions of mobile electrons much more reduced in the former type of complexes than in the latter type of complexes owing to the presence of neutral TCNQ. Complexes $\mathbf{1}, \mathbf{2}, \mathbf{3}$, and $\mathbf{4}$ were much less conductive than the original TCNQ salts, $\mathrm{Na}^{+} \mathrm{TCNQ}^{-}$, and $\mathrm{K}^{+} \mathrm{TCNQ}^{-}$. This may be explaind in terms of the steric hindrance of polymer 5: TCNQ molecules are very much separated from each other, giving rise to low conductivities of the complexes. Most of the polycation-TCNQ complexes were much more conductive than polymers 1-4, which may be explained as follows. Since the separation of the cation sites of polycation-TCNQ complexes is less than that in the crown ether-TCNQ polymers, the TCNQ molecules are also separated to a lesser extent in the former than in the latter complexes.

\section{Electronic Reflection Spectra}

The low electrical conductivities of polymers 14, suggest that the TCNQ molecules in the polymers are in an isolated state. This was confirmed by the
Table I. Electrical resistivities of the complexes of alkali-metal-TCNQ salts with a crown ether polymer, polycation-TCNQ salts, and original TCNQ salts

\begin{tabular}{cc}
\hline & \multicolumn{1}{c}{ Electrical resistivities } \\
\cline { 2 - 2 } Complexes & \multicolumn{1}{c}{$\Omega \mathrm{cm}$} \\
\hline $\mathbf{1}$ & $2.5 \times 10^{9}$ \\
$\mathbf{3}$ & $8.1 \times 10^{6}$ \\
$\mathbf{4}$ & $6.2 \times 10^{9}$ \\
& $1.6 \times 10^{5}$ \\
Polycation-TCNQ & $10^{1}-10^{12}$ \\
complexes & $3 \times 10^{4}$ \\
$\mathrm{Na}^{+} \mathrm{TCNQ}$ & $5 \times 10^{3}$ \\
$\mathrm{~K}^{+} \mathrm{TCNQ}^{-}$ &
\end{tabular}

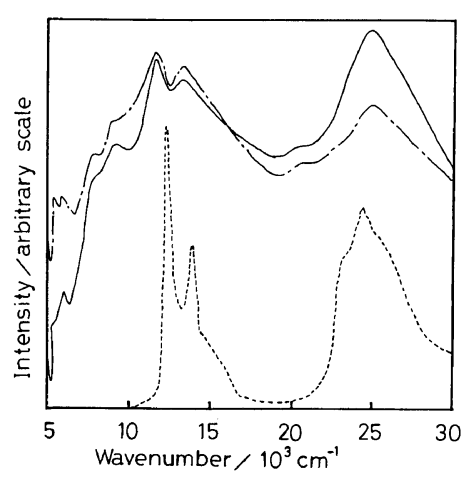

Figure 1. Electronic diffuse reflection spectra of the complexes and electronic absorption spectra of TCNQ salt in acetonitrile solution: - , polymer $1 ;---$, polymer 3; -----, $\mathrm{K}^{+} \mathrm{TCNQ}^{-}$in acetonitrile solution.

diffuse reflection spectra of the polymer complexes. Figure 1 illustrates the diffuse reflection spectra of polymers 1 and $\mathbf{3}$ and the absorption spectra of $\mathrm{K}^{+} \mathrm{TCNQ}^{-}$in an acetonitrile solution. The spectra of polymers $\mathbf{1}$ and $\mathbf{3}$ show two absorption bands at $11.6 \times 10^{3} \mathrm{~cm}^{-1}$ and $12.3 \times 10^{3} \mathrm{~cm}^{-1}$, which are located near the absorption peak of $\mathrm{K}^{+} \mathrm{TCNQ}^{-}$in the acetonitrile solution. Thus, $\mathrm{TCNQ}^{-}$is likely to be in a relatively isolated state. Since electrical conduction occurs as a result of overlapping of the $\pi$-electron orbitals of TCNQ molecules, the isolated structure of $\mathrm{TCNQ}^{-}$is in agreement with the poor conductivities of polymers $1-4$. The instability of the complexes in the air may also be attributed to the same mechanism, since free $\mathrm{TCNQ}^{-}$is easily 
oxidized with oxygen.

\section{REFERENCES}

1. K. Matsuoka, T. Nogami, T. Matsumoto, H. Tanaka, and H. Mikawa, Bull. Chem. Soc. Jpn., 55, 2015 (1982), and references cited therein.

2. K. Mizoguchi, S. Kajiura, A. Nakano, H. Tsuchida, and I. Shinohara, Nihon Kagaku Kaishi, 1404 (1975), and references cited therein.

3. W. M. Feigenbaum and R. H. Michel, J. Polym. Sci.,
$A-1,9,817$ (1971); E. Schchori and J. J. Grodzinski, J. Appl. Polym. Sci., 20, 1665 (1976). The elemental analysis of the polymer $\mathbf{5}$ did not give agreement with the calculation probably due to the contamination of $\mathrm{HCl}$ as the ammonium salt (Found: $\mathrm{C}, 61.67 \% ; \mathrm{H}$, $5.42 \%$. Calcd for $\left(\mathrm{C}_{28} \mathrm{H}_{28} \mathrm{~N}_{2} \mathrm{O}_{8}\right)_{n}: \mathrm{C}, 64.61 \% ; \mathrm{H}$, $5.42 \%$ ).

4. Homogeneous polymer film could not be obtained by the evacuation at higher temperature than $30^{\circ} \mathrm{C}$.

5. L. R. Melby, R. J. Harder, W. R. Hertler, M. Mahler, R. E. Benson, and W. E. Mochel, J. Am. Chem. Soc., 84, 3374 (1962). 